\title{
Radiological progression and lung function in silicosis: a ten year follow up study
}

\author{
TZE-PIN NG， SHIU-LUN CHAN， KA-PING LAM
}

\begin{abstract}
Chest radiographs and spirometric tests were performed on 81 patients who had silicosis from two granite quarries in 1975, 73 of whom were followed up for two to 10 (mean 7.2) years. Each patient's initial and most recent chest radiographs were assessed independently by three experienced readers, and the yearly declines in forced expiratory volume in one second and forced vital capacity were estimated from two to four (mean 3.45) serial spirometric readings. Estimates of individual dust exposure were based on extensive historical data on hygiene. All but 11 patients were no longer exposed to dust by the start of follow up, but 24 $(45 \%)$ of 53 patients who had simple silicosis and $11(55 \%)$ of 20 who had the complicated disease showed radiological evidence of disease progression. In patients who had simple silicosis and showed no radiological progression the yearly declines in forced expiratory volume in one second and forced vital capacity were modest (64 ml/year and $59 \mathrm{ml} /$ year, respectively), whereas significantly greater declines in lung function were seen in those who showed radiological evidence of progression $(97 \mathrm{ml} /$ year and $95 \mathrm{ml} /$ year, respectively). In addition to radiological progression the previous average dust concentration to which patients had been exposed also influenced declines in both forced expiratory volume in one second and forced vital capacity after allowing for the effects of age, smoking, duration of exposure, history of tuberculosis, initial state of disease, and baseline lung function. The probability of radiological progression was most strongly influenced by the average dust concentration previously exposed to.

The progression of simple silicosis is thus accompanied by appreciable declines in lung function and is strongly affected by previous levels of exposure to dust.
\end{abstract}

\section{Introduction}

Many studies have reported varied findings of abnormal lung function in silicosis, as the disease is often complicated by the effects of exposure to mixed dust, mycobacterial and other infection, the presence of massive fibrosis, and conditions related to smoking, such as chronic bronchitis, airway obstruction, or emphysema. ${ }^{12}$ Simple nodular silicosis is widely thought to be associated with little or no functional abnormality, whereas the more advanced complicated disease may be accompanied by restrictive, obstructive, and mixed patterns of ventilatory impairments. ${ }^{1}$

These observations of ventilatory function in silicosis have almost all been derived from cross sectional studies, and few longitudinal studies of changes in lung function in silicosis have been reported. Serial testing of lung function in silicosis is desirable, as the course of progression of the ordinary form of the disease has not been studied adequately. ${ }^{3}$ It has been assumed that progression of simple silicosis would probably not be accompanied by an excess decline in

Occupational Health Division, Labour Department, Hong Kong

TZE-PIN NG, MB, FACOM, occupational health officer

Chest Services, Medical and Health Department, Hong Kong

SHIU-LUN CHAN, MB, MRCP, clinical consultant

KA-PING LAM, MB, BS, medical officer

Correspondence to: $\mathrm{Dr} \mathrm{T} P \mathrm{Ng}$, Occupational Health Division, Labour Deparment, 15th Floor Harbour Building, 38 Pier Road, Hong Kong. lung function until massive fibrosis supervened. In this study we tried to determine if this is indeed so and to identify factors affecting the progression of the disease in a group of granite workers who had silicosis and who were followed up for 10 years.

\section{Patients and methods}

The patients who had silicosis in this study belonged to a cohort of about 350 workers from two granite quarries identified at the start of a medical surveillance programme in 1967. Cases of silicosis identified from annual radiographic screening with large sized films were medicolegally assessed for disability compensation and subsequently followed up with periodic radiographic and lung function examinations at a special pneumoconiosis clinic from 1975 onwards. Between 1967 and 1981, 91 cases of silicosis were medicolegally confirmed. Of these, 81 patients $(89 \%)$ who had silicosis and were still alive and could be traced between 1975 and 1981 were enrolled in the study.

\section{RADIOGRAPHIC READINGS}

Each man's initial radiograph in 1975 or thereafter was read independently by three experienced readers according to the 1980 International Labour Organisation International Standard Classification of Pneumoconiosis. The films were randomly interspersed among other sets of quarry workers' radiographs, which the readers read without knowing the workers' history of exposure. The criterion for inclusion in the study was a reading, agreed by at least two of the three readers, of small opacities of profusion $1 / 0$ or greater in a worker who had also been medicolegally confirmed as having silicosis as a result of his work in either of the two quarries. The profusion of small opacities for each radiograph was taken to be the median of the three readings. The type of small opacities (which was recorded using two characters-for example, pp, ps, ss) was assessed by taking the majority reading of the first letter of the pair (which denotes ihe predominant type of opacities). For example, given three readings such as $p, q$, and $t$, the majority reading for shape and size was $q$ (rounded, $1.5-3 \mathrm{~mm}$ ). In a few instances in which one reader recorded $0 / 0$ or $0 /$ - the other two readers always gave readings for irregular or rounded opacities, or both. The presence of large opacities or other complications, such as tuberculosis, pleural thickening, and emphysema, was recorded in a similar fashion, with the smallest recorded size of large opacities being always favoured by convention. Based on their initial film readings the patients were classified at initial follow up as having simple silicosis if only small opacities (rounded or irregular) were present or as having complicated silicosis if small opacities, together with large opacities or one or more signs of other complications, were present.

Each patient's initial and most recent films were read in random order as described above. Each reader's chronological set of readings was then assessed for radiological progression in the following way. The number of incremental or decremental steps of change along the scale of the International Labours Organisation notations for small opacities was counted, and an increase in radiological profusion was recorded if there were two or more incremental steps of change between the initial and most recent films; where decremental steps were recorded, these were regarded as nonprogression. Similarly, an increase in the size of small opacities was recorded if the most recent film showed a change of one or more incremental steps along the notation scale. The patient was recorded as developing large opacities if the most recent film showed such opacities to be present where none had been recorded on the initial film, and an increase in the size of large opacities was recorded if the most recent film showed incremental changes along the scale. Signs of pleural thickening were recorded in the same manner.

If the decision was not unanimous the majority of two of the three readers was accepted. No attempts were made to assess progression from signs of emphysema, bullae, tuberculosis, and so on, among cases of complicated disease. 


\section{LUNG FUNCTION}

Serial tests of lung function were performed on the same regularly calibrated spirometer (vitalograph) according to standard procedures. The maximal values of forced expiratory volume in one second and forced vital capacity in litres, corrected for body temperature, pressure, and saturation, were recorded from three satisfactory readings. For each variable of lung function a patient's yearly rate of change was computed by linear regression of his observed values on time.

\section{QUESTIONNAIRE INFORMATION}

At initial follow up a detailed history of occupation, smoking habits, and medical treatment was taken for each patient. The information on job history included the first year of employment in either of the two quarries, the nature, location, and duration of each job ever held in either one or both quarries in chronological order, and the nature of any respiratory protection used. The smoking history included the number of cigarettes smoked, the the equivalent of $0.1 \mathrm{mg} / \mathrm{m}^{3}$ respirable quartz to 10 million particles $/ \mathrm{ft}^{3}$ of granite dust ${ }^{4}$ and multiplied by $0 \cdot 5$. (The results in this paper, however, are expressed as $\mathrm{mg}$ respirable quartz/ $\mathrm{m}^{3}$.) The workers' exposure to dust between 1976 and 1981 was assumed to be the same as in 1982 . In quarry B the workers' exposure to dust between 1971 and 1975 was assumed to be the same as in 1971 and from 1976 to 1981 was assumed to be the same as in 1982.

Though extensive dust measurements were available for job locations at or around the crusher and asphalt plants and for manual stone breaking, none was available for rock drilling jobs until 1982. It was known, however, that dust concentrations during rock drilling had always been high, with no improvement in dust control attempted. Levels of dust exposure for rock drillers were hence based on the results of hygiene assessment in 1982. The level of dust exposure for the only tool grinder in the group could not be estimated, so this was left excluded from the analysis.

The lifetime exposure to silica for each patient was estimated by totalling the dust concentrations specific for the job and calendar year and duration of exposure and was expressed as $\left(\mathrm{mg} / \mathrm{m}^{3}\right) \times$ year thus: $\mathrm{Kj} \times \mathrm{Tj}$, where $\mathrm{K}=$ median dust concentrations $\left(\mathrm{mg} / \mathrm{m}^{3}\right.$ quartz), $\mathrm{T}=$ time in years, and $\mathrm{j}=$ job category. For each patient an average level of dust exposure weighted by the duration of exposure was calculated.

TABLE I-Hygiene monitoring data on estimated average dust concentration $\left(\mathrm{mg} / \mathrm{m}^{3}\right.$ respirable quartz) by quarry site and job location

\begin{tabular}{|c|c|c|c|c|c|c|c|c|c|c|c|}
\hline \multirow[b]{2}{*}{ Job location } & \multicolumn{11}{|c|}{ Year of survey } \\
\hline & 1953 & 1956 & 1957 & 1959 & 1960 & 1962 & 1967 & 1969 & 1970 & 1973 & 1982 \\
\hline \multicolumn{12}{|c|}{ Quarry A (started operation in 1946): } \\
\hline Stone breaking & 0.31 & & & & & & & & & & \\
\hline $\begin{array}{l}\text { Primary crusher } \\
\text { Secondary }\end{array}$ & 1.55 & 0.16 & & $0 \cdot 17$ & 0.15 & & & & & & $0 \cdot 27$ \\
\hline $\begin{array}{l}\text { crushers } \\
\text { Screening } \\
\text { Asphalt mixer }\end{array}$ & $\begin{array}{l}1.80 \\
1.25\end{array}$ & $\begin{array}{l}0.29 \\
0.32 \\
0.21\end{array}$ & 0.13 & $0 \cdot 17$ & $0 \cdot 15$ & & & & & & $\begin{array}{l}0 \cdot 10 \\
0.19 \\
0.03\end{array}$ \\
\hline \multicolumn{12}{|c|}{ Quarry B (started operation in 1955): } \\
\hline $\begin{array}{l}\text { Primary crusher } \\
\text { Secondary }\end{array}$ & & & & & & 0.29 & 0.05 & 0.08 & 0.03 & & 0.42 \\
\hline crusher & & & & & & 0.31 & $0 \cdot 11$ & $0 \cdot 10$ & 0.04 & & $0 \cdot 24$ \\
\hline Tertiary crusher & & & & & & $0 \cdot 33$ & 0.13 & 0.15 & 0.04 & & \\
\hline Screening & & & & & & 0.28 & & 0.04 & & & $0 \cdot 11$ \\
\hline Holding bins & & & & & & 0.36 & & & & & 0.46 \\
\hline Asphalt mixer & & & & & & 0.42 & $0 \cdot 28$ & & & $0 \cdot 14$ & \\
\hline
\end{tabular}

Levels of dust exposure based on 1982 hygiene assessment were also assigned to: rock driller $0.93 \mathrm{mg} / \mathrm{m}^{3}$, rock drillers' labourer and shotfirer $0.06 \mathrm{mg} / \mathrm{m}^{3}$, dumper driver $0.04 \mathrm{mg} / \mathrm{m}^{3}$, and loader operator $0.04 \mathrm{mg} / \mathrm{m}^{3}$.

duration of smoking, and the year of stopping. A history of treatment for pulmonary tuberculosis, verified from the clinical records and the results of bacteriological examination whenever possible, was recorded for every patient. At each follow up visit the information on smoking and on exposure to dust while working was updated.

\section{EXPOSURE TO DUST}

Estimates of previous levels of exposure to dust related to various job locations were obtained from extensive past assessments of hygiene in both quarries. Dust concentrations were measured with midget impingers and konimeters at half hourly intervals throughout a working day at various job locations and at various times in the year. The serial results of dust concentrations in the air were available from 1953 to 1960 in one quarry (A) and from 1960 to 1970 in the other quarry (B) (table I). The dust concentrations before hygiene assessment were assumed to be the same as in 1953 for quarry A and as in 1960 for quarry B. Because of a reduction in dust concentrations owing to improved dust control over the period of regular hygiene assessment no further environmental monitoring was subsequently carried out. A hygiene reassessment in 1982, however, showed that environmental dust concentrations were again high and of a magnitude similar to that in the years before dust control improved. We do not think, however, that the lack of data on dust concentrations in subsequent years had much effect on the estimates of individual dust exposure in this group of workers who had silicosis, as the disease was diagnosed in most of them in the 1960 s and early 1970 s, leading promptly to their transfer out of the quarries to other non-dusty jobs.

In quarry $A$ the dust concentration at the crushing plant from 1961 to 1965 was assumed to be the same as in 1960, and for 1965 to 1970 this was multiplied by $1 \cdot 5$. For dust exposure between 1971 and 1975 we converted the respirable silica concentrations measured gravimetrically and with $x$ ray diffraction for quartz determination in 1982 to particle count measures using
TABLE II-Baseline lung function and other characteristics of patients at initial examination

\begin{tabular}{|c|c|c|c|c|}
\hline \multirow{3}{*}{$\begin{array}{l}\text { Age (years) } \\
\text { Height (m) } \\
\text { Smoking habits (No (\%) of patients): } \\
\text { Non-smokers } \\
\text { Past smokers } \\
\text { Current smokers } \\
\text { Current smokers (pack years) }\end{array}$} & \multicolumn{2}{|c|}{$\begin{array}{l}\text { Simple silicosis } \\
\quad(n=58)\end{array}$} & \multicolumn{2}{|c|}{$\begin{array}{l}\text { Complicated silicosis } \\
\qquad(\mathrm{n}=23)\end{array}$} \\
\hline & $\begin{array}{c}52.9 \\
1.62\end{array}$ & $\begin{array}{l}(5 \cdot 3) \\
(0 \cdot 06)\end{array}$ & $\begin{array}{c}54.8 \\
1.64\end{array}$ & $\begin{array}{l}(5 \cdot 8) \\
(0 \cdot 06)\end{array}$ \\
\hline & $\begin{array}{c}14 \\
7 \\
37 \\
254\end{array}$ & $\begin{array}{l}(24) \\
(12) \\
(64) \\
(17 \cdot 1)\end{array}$ & $\begin{array}{c}4 \\
5 \\
14 \\
23 \cdot 9\end{array}$ & $\begin{array}{l}(17) \\
(22) \\
(61) \\
(13 \cdot 1)\end{array}$ \\
\hline $\begin{array}{l}\text { Dust exposure: } \\
\text { Cumulative dose }\left(\left(\mathrm{mg} / \mathrm{m}^{3}\right) \times \text { year }\right) \\
\text { Exposure years } \\
\text { Average silica concentration }\left(\mathrm{mg} / \mathrm{m}^{3}\right) \\
\text { Forced expiratory volume in one second }(\mathrm{l}) \\
\% \text { Of predicted value } \\
\text { No }(\%) \text { with }<75 \% \text { predicted value } \\
\text { Forced vital capacity }(\mathrm{l}) \\
\% \text { Of predicted value } \\
\text { No }(\%) \text { with }<75 \% \text { predicted value }\end{array}$ & $\begin{array}{c}11 \cdot 0 \\
23 \cdot 7 \\
0 \cdot 46 \\
2 \cdot 406 \\
94 \cdot 0 \\
10 \\
3 \cdot 097 \\
96 \cdot 5 \\
7\end{array}$ & $\begin{array}{l}(6 \cdot 9) \\
(5 \cdot 0) \\
(0 \cdot 28) \\
(0.530) \\
(17 \cdot 5) \\
(17) \\
(0.610) \\
(15 \cdot 7) \\
(12)\end{array}$ & $\begin{array}{c}12 \cdot 7 \\
22 \cdot 5 \\
0 \cdot 57 \\
2 \cdot 118 \\
83 \cdot 6 \\
6 \\
2 \cdot 796 \\
86 \cdot 7 \\
6\end{array}$ & $\begin{array}{l}(6 \cdot 8) \\
(4 \cdot 2) \\
(0 \cdot 31) \\
(0 \cdot 611)^{\star} \\
(23 \cdot 7)^{\star} \\
(26) \\
(0 \cdot 618)^{\star} \\
(18 \cdot 4) \dagger \\
(26)\end{array}$ \\
\hline
\end{tabular}

${ }^{\star} \mathrm{p}<0.05 .+\mathrm{p}<0.02$.

\section{STATISTICAL ANALYSIS}

The data were analysed by analysis of variance, $\chi^{2}$ tests, and multiple regression as appropriate. Because of the skewed distribution of dust exposure indices the non-parametric Mann Whitney $U$ test and logarithmic transformation of data were also used. Analysis of covariance was used to adjust for age, smoking, and baseline values when comparing mean lung function among groups, with the general linear modelling procedure in the statistical analysis system (SAS) sof tware package. ${ }^{5}$ The LOGIST procedure ${ }^{6}$ was also used to perform logistic multiple regression for categorical data. 
Results

\section{STUDY POPULATION}

The 81 original subjects ranged in age from 42 to 68 (mean 53.4) years. Their duration of employment in the quarries ranged from 14 to 35 (mean 23.3) years. Fifty men had worked in various jobs at or around the crusher and asphalt plants, four had been manual stonebreakers, 16 were rock drillers or related workers, and one was a toolgrinder, while the rest had worked in various jobs in the quarries. Virtually all of the workers had worked with little or no respiratory protection until the 1970s. The estimated average dust concentrations to which they had been exposed ranged from 0.03 to 1.07 (mean 0.45 ) $\mathrm{mg} / \mathrm{m}^{3}$.

TABLE III-Baseline characteristics of patients. All values are means (SD) unless otherwise stated

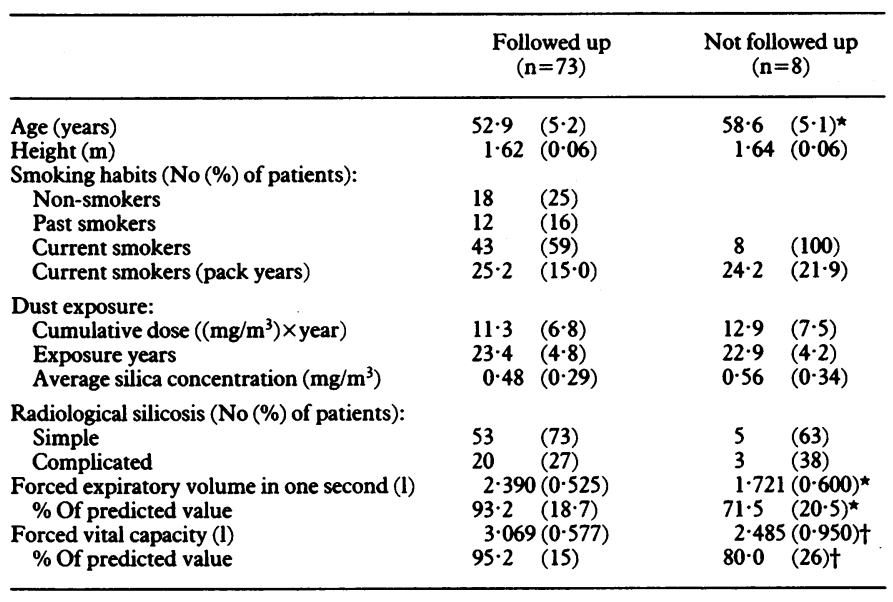

${ }^{\star} \mathrm{p}<0.01 .+\mathrm{p}<0.02$ other problems included emphysema and bullae (one), calcification in small opacities (one), and enlarged hilar lymph nodes (one). In eight men more than one sign of other complications was present.

Lung function was manifestly reduced in men who had complicated disease (table II). For example, forced vital capacity in patients who had simple silicosis was only about $4 \%$ below the predicted values, whereas it was about $13 \%$ below predicted values in those who had the complicated disease. Smoking habits were similar in both groups, and the level of dust exposure was higher in those who had complicated disease.

\section{LONGITUDINAL STUDY}

Eight of the 81 subjects failed to return for at least one follow up visit. Two died after entry into the study, both from primary liver cancer. Men who were lost to follow up were significantly older than those who remained and had had a higher level of exposure to dust; all were smokers with an appreciably lower baseline lung function (table III). The men who were successfully followed up were hence probably a survivor population. The duration of follow up varied from two to 10 (mean $7 \cdot 2$ ) years. The number of repeated tests of lung function in each patient varied from two to four (mean 3.45 ). Of the 73 people for whom serial radiographs were available, $35(48 \%)$ showed radiological evidence of progression. From the initial radiological state of the disease $24(45 \%)$ of 53 men who had simple silicosis and 11 of 20 (55\%) men who had complicated disease showed evidence of progression.

The mean (SD) declines in forced expiratory volume in one second and forced vital capacity were $79(49) \mathrm{ml} /$ year and $75(53) \mathrm{ml} / \mathrm{year}$, respectively, in men who had simple silicosis and 84 (45) $\mathrm{ml} /$ year and 88 (42) $\mathrm{ml} /$ year, respectively, in those who had complicated disease. In both groups those who showed radiological evidence of disease progression had significantly greater rates of decline in lung function than those who did not show such progression (table IV). These differences were highly significant after adjusting for small differences in baseline ventilatory capacity, age, and smoking habits. In those who had complicated disease we suggest that those who did not progress (or stopped progressing) were older, were heavier smokers, and had lower baseline values of lung function at the initial examination. The rates of decline in lung function were also significantly

TABLE IV-Declines in lung function and related baseline variables by radiological form of silicosis and state of progression. All values are means $(S E M)$ unless otherwise stated

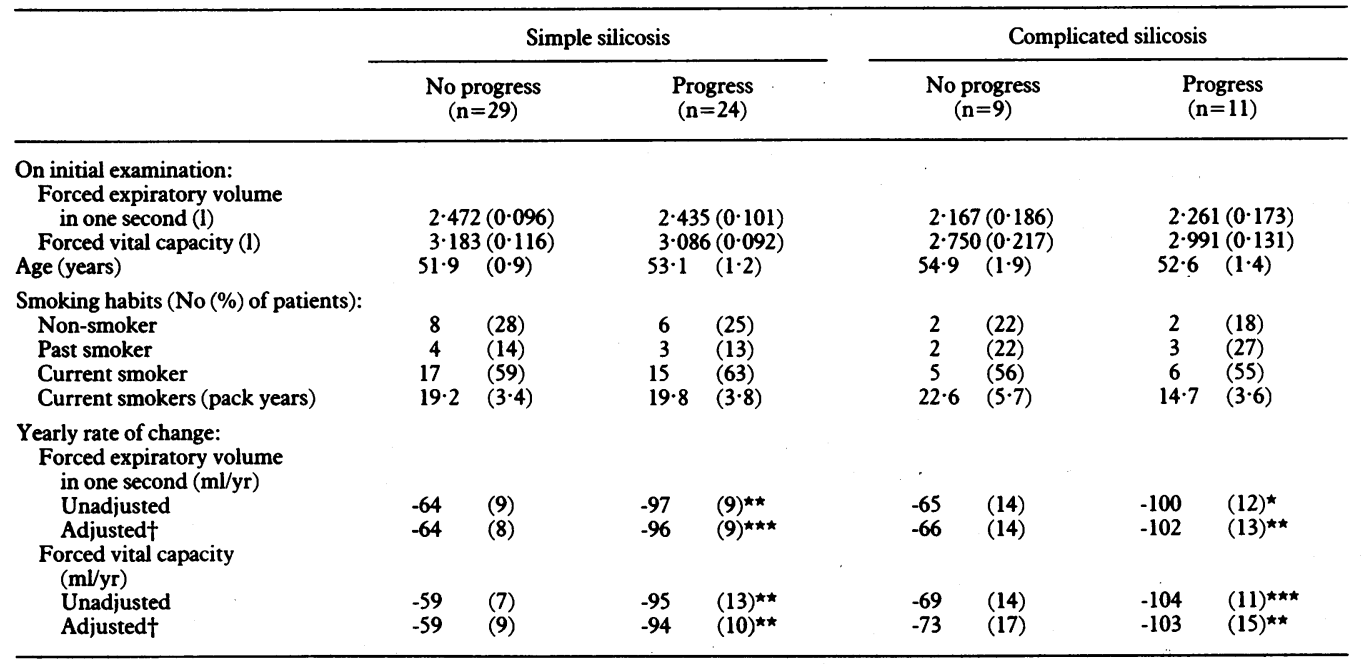

${ }^{\star} \mathrm{p}<0.05,{ }^{\star \star} \mathrm{p}<0.02,{ }^{\star \star \star} \mathrm{p}<0.01$. $\dagger$ Adjusted for age at follow up, smoking (pack years), and lung function on initial examination.

Analysis of the airborne dust by both infrared spectophotometry in the past and $x$ ray diffraction in recent years consistently showed a mean quartz content of around $28 \%$. Fifty two patients had already stopped working at the quarries up to 14 years before the initial examination, and another 11 stopped being exposed shortly after the initial examination, but 11 continued to work at the quarries for up to four years during follow up. Fifty one men $(63 \%)$ currently smoked cigarettes, and $12(15 \%)$ had smoked in the past; most of these gave up smoking because of poor respiratory health.

From initial $x$ ray films 58 men $(72 \%)$ were classified as having simple silicosis and 23 men $(28 \%)$ as having complicated silicosis. Among those who had complicated disease large opacities were recorded in 11 men, tuberculosis in 10 , pleural thickening in three, and eggshell calcification in four, while greater in men whose disease showed evidence of radiological progression after adjusting for differences in age, smoking, and baseline value of lung function.

As the figure shows, the rates of decline in forced vital capacity among men who had simple silicosis and who did not show radiological progression, though generally modest, nevertheless showed great individual variation, particularly in those men in whom the size of opacities was greater than $1.5 \mathrm{~mm}$ ( $\mathrm{q}, \mathrm{t}$, and above). In one patient the decline in forced vital capacity was, at $182 \mathrm{ml} /$ year over five years, unusually rapid for the group he was in; he was the only tool grinder in the study, suggesting that his exposure pattern might be rather unusual for the group. An increased profusion of small opacities alone seemed to be associated with little or no greater increase 
in the yearly decline in forced vital capacity, whereas an increase in the size of small opacities or the development of large opacities seemed to be associated with a greater yearly decline. Considerably greater declines in forced vital capacity were seen in those who developed other complications, such as emphysema, pleural thickening, and effusion. One man, who developed pneumothorax, showed an unusually rapid decline in forced vital capacity at $283 \mathrm{ml} /$ year, which did not correspond with his moderate level of exposure to dust. progression and level of dust exposure after allowing for age, smoking, duration of exposure, initial disease category, and baseline level of lung function. A history of tuberculosis also seemed to be significantly related to a decline in forced expiratory volume in one second $(p<0.05)$ but not in forced vital capacity. As the unusually large decline in lung function in the patient who had pneumothorax greatly affected the analysis by its statistical outlying position his results were excluded in a repeat analysis, which still gave similar results. Similar results were also obtained when the analysis was

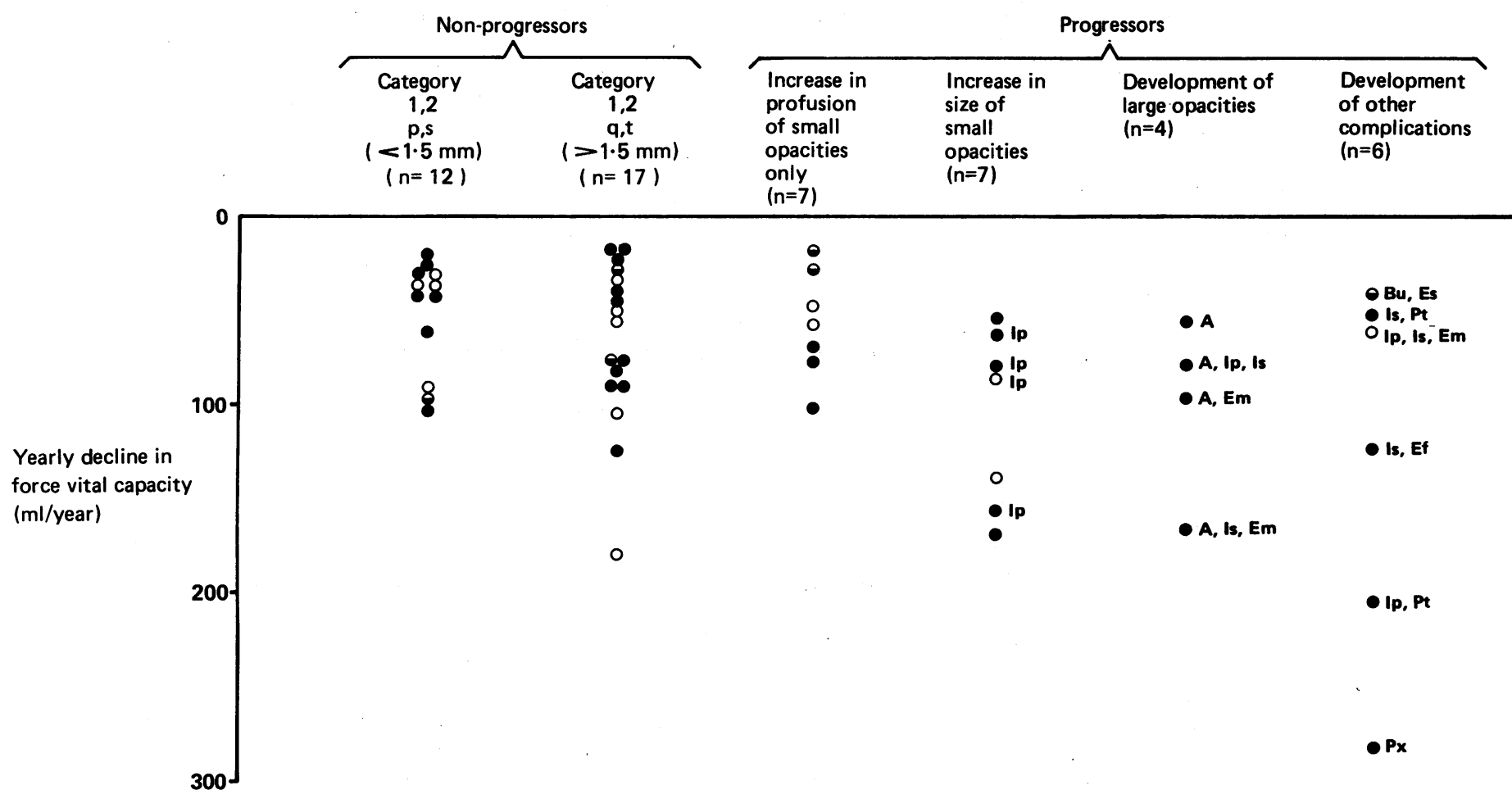

Yearly declines in forced vital capacity of patients who had simple silicosis. $\bigcirc=$ Non-smoker. $\ominus=$ Past smoker. $\bigcirc=$ Current smoker. A=Large opacity, category A. $\mathrm{Bu}=$ Bullae. Ef =Effusion. Em=Emphysema. Es=Eggshell calcification. Ip=Increase in profusion of small opacities. Is=Increase in size of small opacities. $\mathrm{Pt}=\mathrm{Pleural}$ thickening. $\mathrm{Px}=$ Pneumothorax.

\section{INFLUENCING FACTORS}

Multiple regression analysis was used to determine the independent influence of several possible explanatory factors on the yearly decline in lung function (table V). Both the forced expiratory volume in one second and the forced vital capacity were significantly influenced by evidence of radiological

TABLE $\mathrm{V}-$ Multiple regression of yearly rate of change in lung function for selected variables

\begin{tabular}{|c|c|c|}
\hline & \multicolumn{2}{|c|}{ Regression coefficient (SEM) } \\
\hline & $\begin{array}{l}\text { Forced expiratory volume in } \\
\text { one second ( } \mathrm{ml} / \text { year })\end{array}$ & $\begin{array}{l}\text { Forced vital capacity } \\
(\mathrm{ml} / \text { year })\end{array}$ \\
\hline \multicolumn{3}{|l|}{ On first examination: } \\
\hline Age (years) & $-0.31(1.77)$ & $-0 \cdot 33(2 \cdot 11)$ \\
\hline Lung function (1) & $-8.5(9 \cdot 0)$ & $-10.6(10.0)$ \\
\hline Smoking (pack years) & $0.02(0.28)$ & $0.38(0.34)$ \\
\hline History of tuberculosis $†$ & $-29 \cdot 7(13 \cdot 7)^{\star}$ & $-26 \cdot 8(16 \cdot 2)$ \\
\hline \multicolumn{3}{|l|}{ Radiological state: } \\
\hline Initial categorył & $15 \cdot 3(12 \cdot 9)$ & $3 \cdot 4(15 \cdot 3)$ \\
\hline Progressiong & $-31 \cdot 2(9 \cdot 2)^{\star \star \star}$ & $-34: 4(10 \cdot 8)^{\star \star \star}$ \\
\hline Age at first exposure (years) & $0.65(1.73)$ & $0.29(2.06)$ \\
\hline \multicolumn{3}{|l|}{ Dust exposure: } \\
\hline $\begin{array}{l}\text { Average silica concentration } \\
\left(\mathrm{mg} / \mathrm{m}^{3}\right)\end{array}$ & $36(17)^{\star}$ & $40(19)^{\star}$ \\
\hline Duration (years) & $-1 \cdot 40(1 \cdot 19)$ & $-1 \cdot 20(1 \cdot 42)$ \\
\hline Coefficient of determination $\left(R^{2}\right)$ & -0.339 & 0.304 \\
\hline
\end{tabular}

${ }^{\star} 0.02<\mathrm{p}<0.05,{ }^{\star \star} \mathrm{p}<0.002,{ }^{\star \star \star} \mathrm{p}<0.001$.

to $=$ No, $1=$ yes.

$\ddagger 0=$ Simple, $1=$ complicated.

$\$ 0=$ Non-progression, $1=$ progression. restricted to cases of simple silicosis diagnosed at the initial examination. Stepwise logistic multiple regression was used to examine the relation between radiological progression and several possible determining factors, including age at initial examination, initial radiological category (simple or complicated), smoking, interval between initial and most recent radiograph, age at first exposure, and average dust concentration and duration of exposure. The probability of radiological progression was most strongly determined by the average dust concentration exposed to, though it was significant only at $0.05<\mathrm{p}<0 \cdot 10$ (data not shown).

\section{Discussion}

We conducted a longitudinal study to follow the radiological progression and changes in lung function and identified likely determining factors related to disease progression in a group of workers who had silicosis. It is apparent that neither the patients who had silicosis in this study nor the total number of medicolegally confirmed cases completely represented all the possible cases of silicosis that occurred in the cohort. We are currently reviewing all the radiographs of the cohort and are certain that early resignation and retirement or deficiencies in screening and confirmation of the disease have excluded others who have similar radiological abnormalities. As no serial data on lung function during the study period were available for these subjects they could not be included.

To assess radiological progression we used the independent method instead of the side by side method of presenting radiographs for comparison. Though Liddel and Morgan have recommended the side by side method, if only for its simplicity, ${ }^{7}$ we eschewed the method because of grave reservations about bias arising from 
knowing the chronological sequence of the films. Though bias is also likely to exist in the independent method, we took precautions to reduce it as much as possible by carefully selecting films of comparable quality for each patient. The independent method tends to show less progression than the side by side method, ${ }^{8}$ so the assessments of radiological changes in our patients are likely to be conservative. Furthermore, the conventions adopted for deciding between different interpretations always favoured that which gave the smallest change in radiological opacities. Among patients who had complicated disease certain conditions, such as tuberculosis, emphysema, bullae, and eggshell calcification, were not assessed for progression and were therefore assumed to be static. This might therefore obscure differences related to disease progression among patients who had complicated disease.

We could find only one other longitudinal study of disease progression in sandblasters who had accelerated silicosis and who were followed up for one to seven (mean 3.75 ) years. ${ }^{9}$ Our study differed from that of Hughes $e t$ al in that we were able to study progression in the usual chronic form of clinical disease over a longer follow up period. In both studies the patients who had silicosis were well defined homogeneous groups of workers with individual estimates of levels of dust exposure based on documented hygiene data.

As expected, we found many (48\%) of the patients who had silicosis, both simple and complicated, progressing in the absence of further exposure to dust and complicated silicosis occuring for the first time after exposure had stopped. The magnitude of declines in lung function in simple silicosis seemed to be modest if they were not accompanied by radiological progression. In those men who showed radiological progression declines in lung function were greater. In particular, an increase in the size of small opacities and the development of large opacities and other complications seemed to be related to excessive loss of lung function. In complicated silicosis the difference in the decline in lung function in relation to radiological progression was also apparent but was not as great, for the reasons already mentioned.

We believe that the magnitude of changes in lung function in patients who have simple silicosis without radiological progression probably does not greatly exceed that expected for the declines related to age and smoking, though, unfortunately, there were no unexposed healthy controls for comparison. "Predicted". declines for age obtained from cross sectional data cannot be used for direct comparisons, as they are almost invariably greater than those obtained from longitudinal studies. ${ }^{10}$ This is believed to be due to the "cohort" effects of past noxious influences on cross sectional observations of lung function. In addition, reference values for longitudinal declines in lung function owing to age are not available because the "learning" effect and systematic survey biases in longitudinal studies allow only internal comparisons of groups within a given survey. ${ }^{11}$

Nevertheless, the magnitude of differences may be appreciated by using the results of longitudinal declines with age in non-diseased unexposed populations as a comparison. The studies of Glindmeyers et $a l$ and Fletcher et al reported declines in forced expiratory volume in one second (for all age groups and smoking categories) of $18 \mathrm{ml} /$ year and $30 \mathrm{ml} /$ year, respectively. ${ }^{1012}$ On the other hand, for subjects aged 44 and over in all smoking categories, Bosse $e t$ al have reported declines in forced expiratory volume in one second of as much as $61-75(50) \mathrm{ml} /$ year. ${ }^{13}$

We found that excessive loss of lung function was significantly related to radiological progression and previous level of exposure to dust. This is in good agreement with the findings of Hughes et al. ${ }^{9}$ As the incidence of tuberculosis in the local population is still high we considered particularly the role of tuberculosis in this study. We could, however, define the part played by tuberculosis only in terms of disease that has been previously treated as discovered from the clinical records. Bacteriological confirmation was lacking in many cases, and the distinction from massive fibrosis was at times unclear. Hence, though an independent effect of tubercular disease in enhancing the decline in forced expiratory volume in one second might be expected, its role in the progression of silicosis remains uncertain.

The estimated level of dust exposure of patients who had silicosis in this study requires closer examination, as it seems to be relevant to the environmental control limits set for exposure to silica. The threshold limit value established by the American Conference of Industrial Governmental Hygienists is $0.10 \mathrm{mg}$ respirable quartz/ $\mathrm{m}^{3} .{ }^{14} \mathrm{On}$ the other hand, the National Institute of Occupational Safety and Health criteria document has recommended a safe concentration of $0.05 \mathrm{mg}$ respirable quartz $/ \mathrm{m}^{3}{ }^{4}$ Though from the data on dust exposure in this study it seems that our patients who had silicosis developed the disease at concentrations below these exposure limits, it should be noted that all but two estimates of dust exposure were in fact above $0.010 \mathrm{mg} / \mathrm{m}^{3}$. The two lowest dust concentrations were $0.03 \mathrm{mg} / \mathrm{m}^{3}$ and $0.06 \mathrm{mg} / \mathrm{m}^{3}$. The first value was the estimate for a worker who was a plant mechanic and subsequently drove a dumper truck in the quarry. Though, as a mechanic, he spent most of his time in the workshop and was therefore assigned a low background exposure, he was also required occasionally to perform repairs and servicing work on the crushers and was thus almost certainly exposed to intermittently high dust concentrations. The second dust value was the estimate for a shotfirer and foreman at the quarrying site who was probably also infrequently exposed to high dust concentrations while standing near pneumatic rock drilling. Both men clearly differed from others in the group in that it was difficult to assign precise personal estimates of dust exposure to them.

Though the conversion factor for dust concentrations from count to mass units was based on extensive studies undertaken to compare impinger count measurements with size selective mass concentrations that were specific for granite working environments, ${ }^{4}$ it should nevertheless be noted that without actual side by side comparisons of the two instruments the conversion factor used might not have been that appropriate for our study. Until more direct and precise conversions for our own data on dust measurements are possible we must emphasise that the exposure estimates in our study should not be used to evaluate current exposure standards. Such considerations, however, should not invalidate the main findings of this study.

We thank the staff of the pneumoconiosis clinic at Wanchai for their help in making this study possible, Albert Cheung Yu Kiu of the department of community medicine, Chinese University of Hong Kong, for his help with the computing, and the director of Medical and Health Services for his interest and support.

\section{References}

1 Seaton A. Silicosis. In: Morgan WKC, Seaton A. Occupational lung diseases. 2nd ed. Philadelphia W B Saunders, 1984.

2 Parkes WR. Silicosis. In: Parkes WR, ed. Occupational lung disorders. 2nd ed. London: Butterworths, 1982 .

3 Ziskind M, Jones RN, Weill H. Silicosis. The state of the art. Am Reo Respir Dis 1976;113:643-65. 4 Utidjian HM. Recommendations for a crystalline silica standard. I Occup Med 1975;17:780.

5 Helwig JT, Council KA, eds. SAS user's guide: statistics. Cary, North Carolina: SAS Institute, 1982:139-99.

6 Reinhart PS, ed. SAS supplemental libray user's guide, 1980 . Cary, North Carolina: SAS Institute, 1980.

7 Liddel FJK, Morgan WKC. Methods of assessing serial films of the pneumoconiosis: a review. f Soc Occup Med 1978;28:6-12.

8 Amandus HE, Reger RB, Pendergrass EP, et al. The pneumoconiosis: methods of measuring progression. Chest 1973;63:736-46.

9 Hughes JM, Jones RN, Gilson JC, et al. Determinants of progression in sandblasters' silicosis. Ann Occup Hyg 1982;26:701-12.

10 Glindmeyers HW, Diem JE, Jones RN, Weill H. Non-comparability of longitudinally and crosssectionally determined annual change in spirometry. Am Rev Respir Dis 1982;125:544-8.

11 Burrows B, Lebowitz MD, Camille AE, Knudson RJ. Longitudinal changes in forced expiratory volume in one second in adults. Am Rev Respir Dis 1986;133:974-80.

12 Fletcher $\mathrm{C}$, Peto R, Tinker C, Spiezer F. The natural history of chronic bronchitis and emphysema. Oxford: Oxford University Press, 1976.

13 Bosse R, Sparrow D, Garvey AJ, Costa PT Jr, Weiss ST, Rowe JW. Cigarette smoking, aging and decline in pulmonary function. A longitudinal study. Arch Environ Health 1980;35:247-52.

14 American Conference of Governmental Industrial Hygienists. Threshold limit values and biological exposure indices for 1986-87. Cincinnati. ACGIH, 1986.

(Accepted 15 April 1987) 